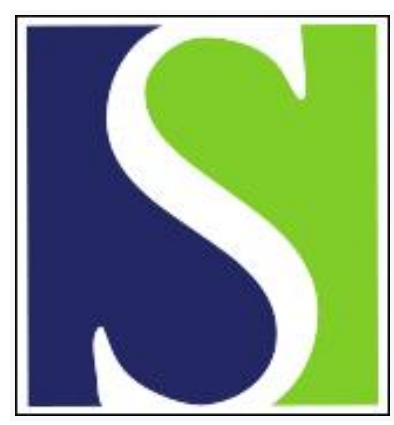

Scand J Work Environ Health 1987;13(4):367-369

https://doi.org/10.5271/sjweh.2042

Issue date: Aug 1987

Clinical neurological methods in the diagnosis of the hand-arm vibration syndrome.

by Farkkila M

Affiliation: Department of Neurology, University Hospital, Helsinki, Finland.

This article in PubMed: www.ncbi.nlm.nih.gov/pubmed/3324316

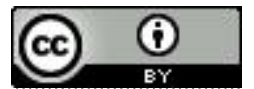




\title{
Clinical neurological methods in the diagnosis of the hand-arm vibration syndrome
}

\author{
by Markus Färkkilä, $M D^{1}$
}

\begin{abstract}
FÄRKKILÄ M. Clinical neurological methods in the diagnosis of the hand-arm vibration syndrome. Scand $J$ Work Environ Health 13 (1987) 367-369. Methods for assessing neurological disturbances in the diagnosis of the hand-arm vibration syndrome are described. The clinical examination should comprise a careful history of symptoms and vibration exposure and a consideration of neurological signs known to be associated with vibration exposure. There is as yet no etiologic diagnostic method for vibration-induced neurological lesions. The best method is a relevant clinical examination as described, in combination with a quantitative assessment of sensory modalities (such as the vibration perception threshold) and an electroneuromyographic test.
\end{abstract}

Key terms: carpal tunnel syndrome, electroneuromyography, median nerve, nerve entrapment, neuropathy, ulnar nerve, vibration perception threshold.

The most prominent sign of the hand-arm vibration syndrome is the vascular disorder previously known as "traumatic vasospastic disease," now called Raynaud's phenomenon or vibration-induced white finger (VWF) $(2,22,26)$. The vascular symptoms appear to be caused both by central sympathetic mechanisms and by a peripheral local lesion in the control of blood flow in the fingers $(20,23)$. In spite of intensive study, the basic pathogenic mechanism of VWF is still unknown. As different mechanisms may underlie the vascular and sensorineural components of VWF, separate clinical classification scales for the two types of symptoms have been proposed $(5,13)$.

Neurological disturbances other than those occurring in connection with VWF have been described for vibration-exposed workers (diffuse neuropathy, carpal tunnel syndrome, etc). The methods suggested for use in the diagnosis of these disorders are as follows: (i) clinical neurological examination, (ii) electroneuromyography, (iii) assessment of somatosensory evoked potentials, (iv) quantitative measurement of sensory modalities, and (v) muscle force measurement. They are all nonspecific with regard to vibration as an etiologic factor.

The best method for diagnosing the neurological disturbances connected with the hand-arm vibration syndrome is still a clinical neurological examination with due consideration of symptom history, vibrationexposure data, and differential etiology. In a large population study (10), only $4 \%$ of a group of lumber-

\footnotetext{
1 Department of Neurology, University Hospital, Helsinki, Finland.
}

Reprint requests to: Dr M Färkkilä, Department of Neurology, University Hospital, Haartmaninkatu 4, SF-00290 Helsinki, Finland. jacks had polyneuropathy. Diminished tendon reflexes in combination with peripheral sensory loss in the upper arms were seen in $7.5 \%$ of the workers. In polyneuropathies of other origin, the lower extremities are first affected, and the quadriceps and gastrocnemius reflexes are first diminished. In the neuropathies seen among lumberjacks (10), the upper arm reflexes are diminished but the quadriceps and gastrocnemius reflexes are unaffected. After the exclusion of other causes, the hand-arm vibration syndrome can be diagnosed on the basis of symptom history and clinical neurological findings known to be associated with vibration exposure. Other methods only support or refute the conclusions made by the physician.

\section{Electroneuromyography}

The electroneuromyogram has been extensively used for the diagnosis of vibration-induced neuropathy. Electroneuromyography may indicate the presence and location of a peripheral nerve lesion. Lukáš (17) found electroneuromyographic changes in $53 \%$ of 108 workers exposed to vibration. These findings were interpreted as possible consequences of spinal disease of the neck, compression in the upper thoracic aperture, disease affecting the elbow joint, and disturbances in the ulnar or median nerves in the hand. In general, the findings were not taken to be causally related to vibration exposure. Lukáš could not state unequivocally that exposure to vibration was the primary cause of the changes he detected, nor could he exclude this possibility.

Changes in the distal latencies of the median nerve have been described to be specific to vibration neuropathy (24), especially in combination with ulnar nerve affection. However, the possible intraneural entrap- 
ment induced by vibration exposure - first described by Ahlborg \& Voog (4) - probably causes this condition, which resembles carpal tunnel syndrome (21). Electroneuromyography is a very sensitive method for demonstrating nerve lesion; the real problem, however, is to show that vibration has caused the lesion.

\section{Assessment of somatosensory evoked potentials}

In clinical practice, the assessment of somatosensory evoked potentials has been recently introduced as a routine method for the study of both the peripheral sensory nerves and the central neural pathways. It appears that this assessment has not yet been used in clinical work for the diagnosis of neurological disturbances in the hand-arm vibration syndrome. Theoretically, it may offer a new way of approaching these nerve lesions. However, sensitive as this method is, it will probably prove to be even more vibration nonspecific than electroneuromyography.

The quantitative measurement of sensory modalities, chiefly the sense of vibration, has been extensively tried in the diagnosis of vibration syndrome $(1,19,25)$. The two-point discrimination test and the assessment of temperature sensitivity have also been used. These tests are psychophysical, and variations in the degree of cooperation of the subject may greatly affect the results. Another problem is that, although the tests are sensitive enough, they normally show a large interindividual variation and therefore cannot be used for individual diagnostics (12). They may, however, be used with advantage in group research. A modified method for the assessment of vibration perception threshold has been developed (8) in which the adaptation of the receptors after vascular occlusion is recorded. The adaptation curve of the vibration perception threshold seems to differentiate better between persons with VWF and those with carpal tunnel syndrome. However, this test, like several of its kind, totally lacks etiologic specificity.

\section{Muscle force measurement}

Whether changes in muscle force form part of the hand-arm vibration syndrome is a question that has been controversial for a long time. Agate and his collaborators (3) rejected this idea, and later work (15) has supported their opinion. Lumberjacks with only VWF have been found to show a higher level of muscle force than lumberjacks with so-called vibration neuropathy $(7,9)$. There is, however, no range of hand muscle force which is known to be "normal." Therefore, muscle force measurements can only be used in group studies, not for individual diagnostics. It should also be remembered that the assessment of muscle force depends to a certain degree on subjective factors.

\section{Differential diagnostic aspects in neurological problems}

In a broad review of polyneuropathies, Freemon (11) did not mention vibration as a cause of generalized nerve lesions. Muscle weakness, numbness, and clumsiness of the hands in persons exposed to hand-arm vibration have been considered, for a long time, as indicating vibration neuropathy $(16,18,24)$. Differential diagnostic problems arise from alcohol consumption, systemic diseases like diabetes, collagenoses, thoracic outlet syndrome, carpal tunnel entrapment, deficiency of vitamins, previous injuries to the hand and arm, etc. Recently, a case report of primary amyloidosis in a vibration-exposed worker has been published (14). In insulin-dependent diabetic patients followed for many years during their vibration work, no signs of polyneuropathy have been seen to develop. In a comparison of teetotallers with heavy alcohol consumers, no relationship was observed between alcohol consumption and symptoms and signs of neuropathy (10).

Carpal tunnel syndrome has been reported to occur more often among vibration-exposed workers than in a normal male population $(4,6)$. The clinical picture of carpal tunnel syndrome that is induced by vibration slightly differs from carpal tunnel entrapment of other origin. The entrapment symptoms in the syndrome are more diffuse, often affecting also the ulnar nerve. It shows good spontaneous recovery after vibration exposure is eliminated. Surgical therapy is seldom needed because of this tendency towards spontaneous recovery (8). At present, it seems that vibration exposure to the hands can cause connective tissue swelling, especially in the carpal canal, and diffuse symptoms of entrapment, particularly of the median nerve. This phenomenon explains both the hand paresthesias and the neurophysiological findings already discussed. Such a condition can develop independently of VWF and should be included as a separate entity of the hand-arm vibration syndrome.

\section{References}

1. Aatola S, Starck J, Pyykkö I, Färkkilä M, Korhonen $O$. Vibration detection threshold of lumberjacks. In: Korhonen $\mathrm{O}$, ed. Proceedings of the international symposium on the protection of workers against vibration. Institute of Occupational Health, Helsinki 1982, pp $88-90$.

2. Agate JN. An outbreak of cases of Raynaud's phenomenon of occupational origin. Br J Ind Med 6 (1949) $144-163$.

3. Agate JN, Druett HA, Tombleson JBL. Raynaud's phenomenon in grinders of small metal castings. $\mathrm{Br} \mathrm{J}$ Ind Med 3 (1946) 167-174.

4. Ahlborg G, Voog L. Vibration exposure and distal compression of the median nerve ("carpal tunnel syndrome") [in Swedish]. Läkartidningen 79 (1982) 4905-4906. (English summary).

5. Brammer AJ, Taylor W, Lundborg G. Sensorineural stages of the hand-arm vibration syndrome. Scand $\mathrm{J}$ Work Environ Health 13 (1987) 279-283.

6. Chatterjee DS, Barrwick DD, Petrie A. Exploratory 
electromyography in the study of vibration-induced white finger in rock drillers. Br J Ind Med 39 (1982) 89-97.

7. Färkkilä M. Grip force in vibration disease. Scand $\mathbf{J}$ Work Environ Health 4 (1978) 159-166.

8. Färkkilä M, Pyykkö I, Jäntti V, Aatola S, Starck J, Korhonen $\mathrm{O}$. Neurological study among vibration exposed forest workers. Br $\mathbf{J}$ Ind Med (in press).

9. Färkkilä M, Pyykkö I, Korhonen O, Starck J. Vibration induced decrease in the muscle force in lumberjacks. Eur J Appl Physiol 43 (1980) 1-9.

10. Färkkilä M, Starck J, Aatola S, Pyykkö I, Korhonen $O$. Vibration induced neuropathy among forest workers. Acta Neurol Scand 71 (1985) 221-225.

11. Freemon FR. Causes of polyneuropathy. Acta Neurol Scand 51 (1975): suppl 59, 8-43.

12. Gemne G. Pathophysiology and multifactorial etiology of acquired vasospastic disease (Raynaud syndrome) in vibration-exposed workers. Scand J Work Environ Health 8 (1982) 243-249.

13. Gemne G, Pyykkö I, Taylor W, Pelmear PL. The Stockholm Workshop scale for the classification of coldinduced Raynaud's phenomenon in the hand-arm vibration syndrome (revision of the Taylor-Pelmear scale). Scand J Work Environ Health 13 (1987) 275-278.

14. Hagberg M, Almay B, Kolmodin-Hedman B, Zetterlund B. Vibration exposure - A modifier of the onset of amyloid neuropathy: A case report. Scand J Work Environ Health 12 (1986) $277-279$.

15. Hellström $B$, Lange-Andersen $K$. Vibration injuries in Norwegian forest workers. Br J Ind Med 19 (1972) $255-263$.
16. Juntunen J, Matikainen E, Seppäläinen AM, Laine A. Peripheral neuropathy and vibration syndrome. Int Arch Occup Environ Health 52 (1983) 17-24.

17. Lukáš $E$. Lesion of the peripheral nervous system due to vibration. Work Environ Health 7 (1970) 67-69.

18. Matikainen E, Juntunen J. Neuropathies due to physical factors and entrapment in occupational neurology. Acta Neurol Scand 66 (1982): suppl 92, 211-218.

19. Miura T, Kimura K, Tominaga Y, Kimotsuki K. On Raynaud's phenomenon of occupational origin due to vibrating tools. J Sci Labour 42 (1965) 725-747.

20. Olsen N. Centrally and locally mediated vasomotor activities in Raynaud's phenomenon. Scand J Work Environ Health 13 (1987) 309-312.

21. Phalen GS. The carpal tunnel syndrome. Clin Orthop 83 (1972) 29-40.

22. Pyykkö I. The prevalence and symptoms of traumatic vasospastic disease among lumberjacks in Finland. Work Environ Health 11 (1974) 118-131.

23. Pyykkö I, Kolari P, Färkkilä M, Starck J, Korhonen $O$, Jäntti V. Finger peripheral resistance during local cooling in vasospastic disease. Scand $\mathrm{J}$ Work Environ Health 12 (1986) 395-399.

24. Seppäläinen AM. Peripheral neuropathy in forest workers: A field study. Work Environ Health 9 (1972) $106-111$.

25. Starck J, Färkkilä M, Aatola S, Pyykkö I, Korhonen $\mathrm{O}$. Vibration syndrome and vibration pedestal grinding. $\mathrm{Br} \mathrm{J}$ Ind Med 40 (1983) 426-433.

26. Taylor W. The vibration syndrome: Introduction. In: Taylor W, ed. The vibration syndrome. Academic Press, London 1974, pp i-xii. 